\title{
MEDICIÓN DEL VOLUMEN GÁSTRICO RESIDUAL MEDIANTE ULTRASONOGRAFÍA EN PACIENTES SOMETIDOS A CIRUGÍA ELECTIVA
}

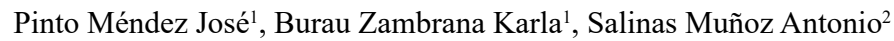

Becado de Anestesiologia y Reanimacion UCSC.

Anestesista Hospital Clinico Herminda Martin de Chillán.

Introducción: Una de las complicaciones más temidas para el anestesista es la broncoaspiración. Se han reportado casos en cirugías electivas y con ayuno correspondiente una incidencia menor al $10 \%{ }^{1}$, pero asociado a una alta morbimortalidad. Mediante el uso de ultrasonografía podemos medir el volumen gástrico residual preoperatorio y anticipar posibles riesgos.

Objetivo General: Mediante un estudio descriptivo se medirá el área transversal del antro gástrico y calcular el volumen gástrico residual mediante ultrasonografía utilizando la fórmula matemática propuesta por Perlas, et al ${ }^{1}$.

Material y Métodos: Se realizaron mediciones del área transversal del antro gástrico mediante ultrasonografía en varias proyecciones del estómago eligiendo para ello las ventanas epigástrica, subcostal y Transesplénica a un total de 30 pacientes entre los 13 y los 78 años de edad, con IMC menor de $40 \mathrm{Kg} / \mathrm{m}^{2}$ y ayuno preoperatorio entre 8 y 15 horas en cirugías electivas. No se tomaron en cuenta comorbilidades asociadas. Para esto se utilizó el equipo SonoSite M-Turbo® con transductor C60xi (Abdominal). Después de realizar la medición del ATG el resultado $\left(\mathrm{en}^{2} \mathrm{~cm}^{2}\right.$ se utilizó para calcular el volumen intragástrico mediante la fórmula propuesta y validada por Anahi Perlas ${ }^{1}$ : Volumen $=27,0+(14,6$ x ATG en $\mathrm{cm}^{2}-1,28 \mathrm{x}$ edad en años). Además indentificar "estomagos de riesgo", descrito por Bouvet ${ }^{2}$ como el volumen gástrico que supera los $0,8 \mathrm{~mL} /$ $\mathrm{kg}$ de peso, medido por ultrasonido transversal a nivel del antro gástrico.

Resultados: Las mediciones realizadas midiendo el área transversal del antro gástrico y según la fórmula de Perlas ${ }^{1}$ obtuvimos volúmenes gástricos esperados según su curva de medición en los pacientes analizados. No hubo ninguna broncoaspiración en nuestros pacientes sometidos a cirugía electiva. De los 6 pacientes menores de 30 años la mitad tenía un estómago de riesgo según Bouvet ${ }^{2}$, sin embargo, no se tuvieron complicaciones. Cabe destacar que dentro de nuestras mediciones existe un paciente con mayor volumen gástrico residual, en los antecedentes destaca ser portador de un Cáncer gástrico, al

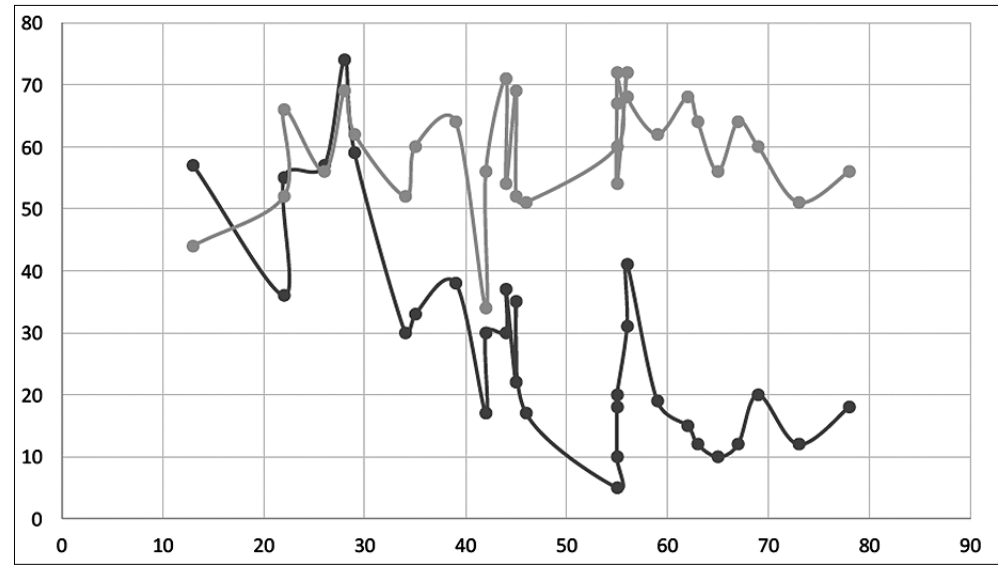

Figura 1. Gráfico descriptivo entre edad de los pacientes, en oscuro volumen gástricoresidual. En claro volúmenes "estómago de riesgo". 
cual se le había instalado una sonda nasogástrica el día anterior de la cirugía. Nuestras mediciones corresponden a un volumen gástrico residual de $148 \mathrm{ml}$. Al ingreso y posterior a la medición se logró aspirar $130 \mathrm{ml}$ de contenido residual, siendo concordante con nuestra medición por ultrasonido. Este es un dato a tener en cuenta puesto que logra respaldar nuestra medición.

Conclusiones: La ecografía es un método fácil, útil y no invasivo que permite medir el área transversal del antro gástrico y así calcular el volumen gástrico residual con el fin de anticipar una posible broncoaspiración. Sería interesante poder analizar las comorbilidades de cada paciente, ya que no se tomaron en cuenta en el estudio y ver cuales logran afectar el vaciamiento gástrico $\mathrm{y}$ con ello el volumen gástrico residual.

\section{Referencias}

1. Perlas A, Mitsakakis N, Liu L, Cino M, Haldipur N, Davis L, et al. Validation of a mathematical model for ultrasound assessment of gastric volume by gastroscopic examination. Anesth Analg. 2013;116:357-363.

2. Bouvet L, Clinical assessment of the ultrasonographic measurement of antral area for estimating preoperative gastric content and volume. Anesthesiology. 2011;114:1086-1092. 